\title{
Notes on the vocalizations of Streaked Wren-babbler (Napothera brevicaudata)
}

Peter Boesman

In the following we briefly analyze and compare voice of the different races of Streaked Wren-babbler (Napothera brevicaudata). We also try to quantify the extent of any vocal differences using the criteria proposed by Tobias et al. (2010), as a support for taxonomic review. We have made use of sound recordings available on-line from Xeno Canto (XC).

HBW (Collar et al. 2016) suggests three distinct groups based on morphology. We will compare song of these three groups:

Rufous group (nominate, striata, rufiventer),

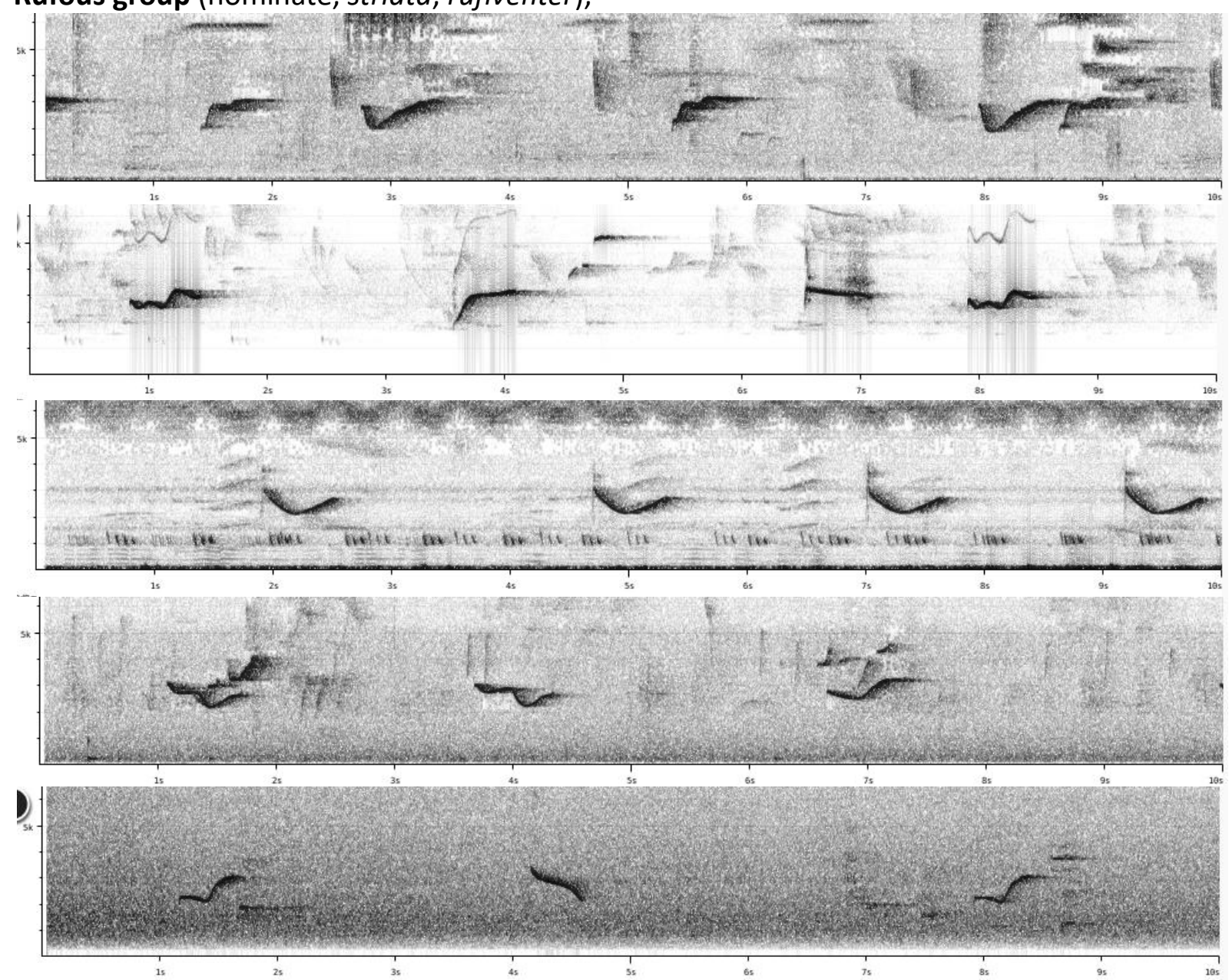




\section{HANDBOOK OF THE \\ BIRDSPFGE WORLD}

Brown group (stevensi, proxima, griseigularis)

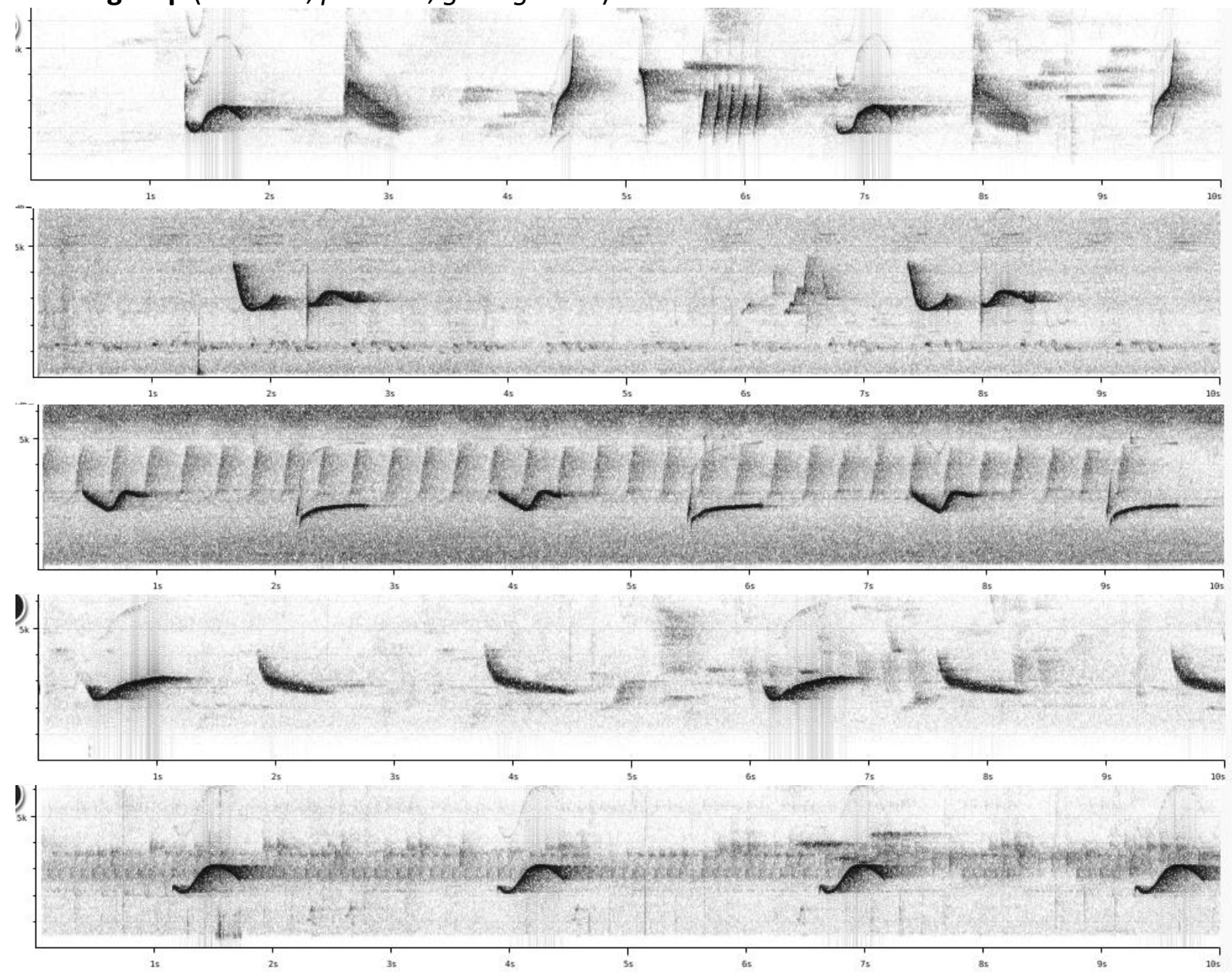

leucosticta
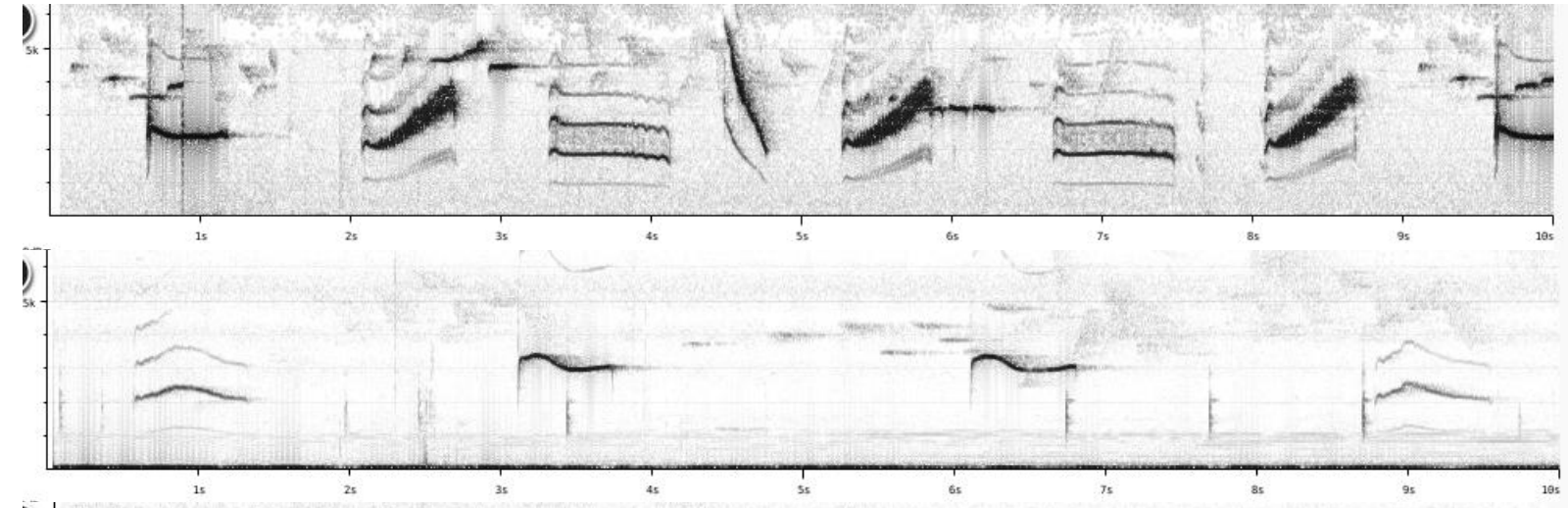

D.

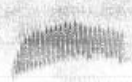

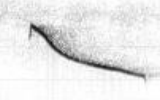

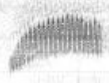

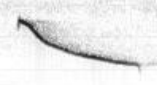

atstones
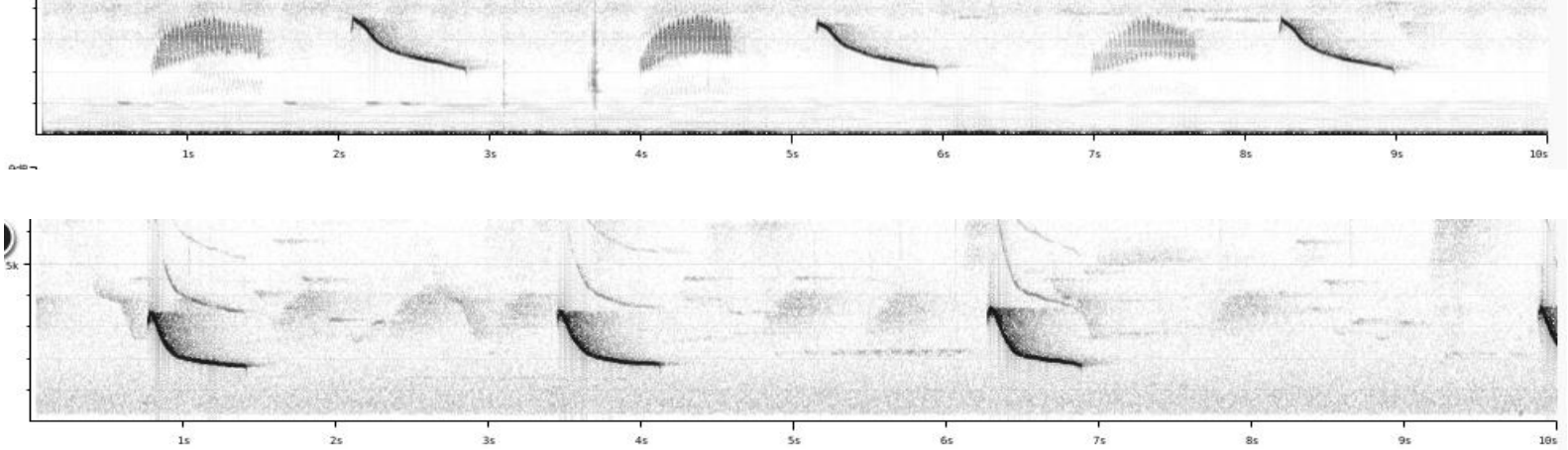

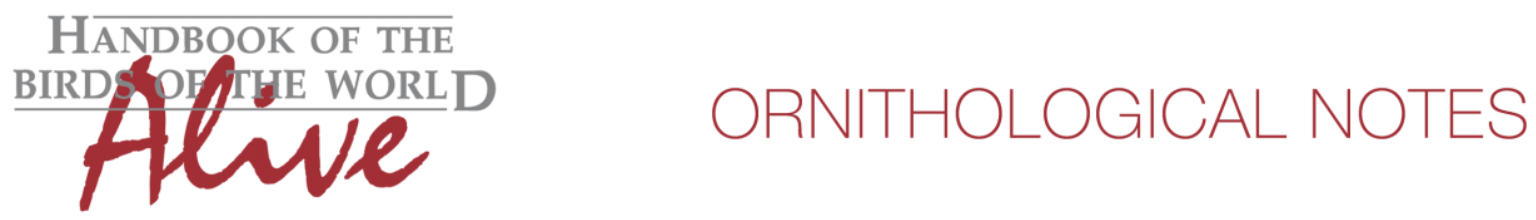

Song of the three groups is quite similar: single (or occasionally double) whistles repeated at intervals. Either the same whistle is repeated or 2 or 3 whistles are alternated.

Basic sound parameters are similar for all groups (note length, min./max. freq., etc.) and a blind recording would not be clearly attributable to any group. There is a large variation of note shapes within each group, and again no clear indication that any group would have unique note shapes, although a more thorough study with a large set of recordings would be needed to prove this.

At this point, we can only conclude that the available recordings do not indicate any significant vocal difference among groups.

This note was finalized on 12th April 2016, using sound recordings available on-line at that moment. We would like to thank in particular the many sound recordists who placed their recordings for this species on XC.

\section{References}

Collar, N. \& Robson, C. (2016). Streaked Wren-babbler (Napothera brevicaudata). In: del Hoyo, J., Elliott, A., Sargatal, J., Christie, D.A. \& de Juana, E. (eds.). Handbook of the Birds of the World Alive. Lynx Edicions, Barcelona. (retrieved from http://www.hbw.com/node/59532 on 12 April 2016).

Tobias, J.A., Seddon, N., Spottiswoode, C.N., Pilgrim, J.D., Fishpool, L.D.C. \& Collar, N.J. (2010). Quantitative criteria for species delimitation. Ibis 152(4): 724-746.

\section{Recommended citation}

Boesman, P. (2016). Notes on the vocalizations of Streaked Wren-babbler (Napothera brevicaudata). HBW Alive Ornithological Note 271. In: Handbook of the Birds of the World Alive. Lynx Edicions, Barcelona. (retrieved from http://www.hbw.com/node/1251712 on 6 October 2016). 